\title{
SPATIAL DIVERSITY IN SMALL-SCALE FISHING: A SOCIO-CULTURAL INTERPRETATION OF THE NILE PERCH SECTOR ON LAKE VICTORIA, UGANDA
}

\section{JOOST BEUVING}

Radboud University, Nijmegen, Cultural Anthropology and Development Studies (CAOS), Thomas van Aquinostraat 4, 6500 HE, Nijmegen, the Netherlands. E-mail: j.beuving@maw.ru.nl

Received May 2013; accepted December 2013

\begin{abstract}
This paper discusses spatial patterns in small-scale fishing in Africa. It is located in Lake Victoria where since the 1990 s a vibrant Nile perch fishing for overseas export developed. Focusing on a very small area in the Ugandan part of the lake, the paper uncovers a larger diversity in fishermen's responses to the dynamic environment of the Nile perch sector than a widely adopted generic model predicts. To understand this better, the paper looks at the social practices of Nile perch fishermen, uncovering the operation of different, spatially situated, fishing styles. These styles structure the social relations that the fishermen mobilise, the symbolic meanings they attach to their gear, and the values that inspire their decision-making. By thus looking at socio-cultural factors the paper hopes to contribute to an emerging spatial perspective on small-scale fishing in Africa that begins with an interest in actual social practice.
\end{abstract}

Key words: Small-scale fishing styles, spatial diversity, Lake Victoria, Uganda, multi-method methodology, socio-cultural perspective

\section{INTRODUCTION}

This paper discusses spatial patterns in smallscale fishing in Africa. It is situated in Lake Victoria where since the 1990s a vibrant export in Nile perch has developed (Dijkstra \& van Donge 2001; Pringle 2005). Whereas large companies dominate the processing, airlifting, and overseas retailing of this commercial table fish, the fishing itself is dominated by smallscale activity (Ruben et al. 2006; Johnson 2010). For the purpose of this paper, it is important to note that a large diversity in fishing practices surrounds the local Nile perch sector. Even a brief visit to the lakeshore shows that in some locations fishing with imported gill nets pre- vails, whereas elsewhere long-lines are more common. The use of outboard engines has become widespread, but sails and paddles continue to be used in particular patches. In some places, fishermen dedicate all their energy to fishing Nile perch, whereas elsewhere fishermen combine it with subsistence fishing, or even with agriculture (Appleton 2000; Béné \& Merten 2008). This paper aims to throw new light on the dynamics driving this spatial diversity by offering a socio-cultural interpretation of small-scale fishing.

Several salient features of the Nile perch fishing sector first need to be considered. Its rapid growth notwithstanding, it remains far from a stable business. On the export side, 
there have been frequent ups and downs in prices and traded volumes during the past fifteen years (Josupeit 2009). Exports depend on global demand for the fish (local/regional Nile perch consumption and trade remain limited): Nile perch competes globally with other inexpensive table fish, notably tilapia and hake. Demand remains dependent, therefore, on market conditions elsewhere on the globe, which are difficult to predict. Adding to this is the long and complicated commodity chain connecting Nile perch to overseas markets (Ponte 2007). The supply side depends primarily on catching the free-ranging Nile perch, and on the production capacity of fish processing factories (not discussed further here). Catches are erratic: Nile perch is a dispersed and highly mobile fish species, which the fishermen find difficult to detect (Balirwa 2007). Moreover, Nile perch fishing on Lake Victoria is a smallscale, artisanal enterprise, with little central co-ordination, so in view of the above-noted uncertainties, individual fortune and failure remain unpredictable (Beuving 2013).

A special problem for social research is to understand how African small-scale fishermen respond to this dynamic environment. The paper shows how previous attempts focused on the lake as a whole, resulting in a generic model wherein fishermen are thought to strike an optimal balance between economic opportunity, risk, and profits. However, there appears to be a problem with this image. It tends to reduce the complexity of human behaviour to a singular, rational response to prevailing external conditions. This procedure may be convenient for the 'quick and dirty' research methods that are currently popular in fisheries development circles (Pitcher \& Preikshot 2001), but a major question remains as to how well a generic model applies when one shifts from looking at the lake as a whole to looking at a particular location at the lake. The paper leans towards a negative answer. Looking at actual social practices in a very small portion of the lake situated in central Uganda covering less than 5 per cent of its surface area - the lake is shared with Kenya and Tanzania - it uncovers a larger diversity in fishermen's responses than is to be expected with the generic model. A detailed deconstruction of these responses reveals that not external factors, but socio- cultural processes that are internal to the studied fishing practices explain the observed spatial diversity.

Fishing gear plays a special role therein. In analyses of small-scale fishing (in Africa, but also elsewhere), fishing gear is usually regarded from a viewpoint of fishing effort: converting manpower into catches (Kolding \& van Zwieten 2011). Conventional indicators for this are number of hours spent on the water; distance travelled during fishing trips; the deployment of inputs notably petrol for propulsion; and the characteristics of fishing gear and boats (Stewart et al. 2010). The paper builds on the associated idea that small-scale fishermen are entrepreneurs making investments in a fishing enterprise (compare Hara \& Jul-Larsen 2003); but to that it adds the socio-cultural meanings fishermen attach to their fishing gear. That is, the fishermen studied in this paper express social relations surrounding their small-scale fishing in terms of the fishing gear they use, or aspire to use. They make a basic social distinction between those using long-lines, or mukonyo, and gill nets, or butimba, to fish for Nile perch. In their view, fishing gear represents not so much a value-neutral resource-tocash convertor as a socio-cultural signifier that structures fishing relations. Hence, an ambition of the paper is to show how the use of fishing gear relates to particular social groups of Nile perch fishermen and to the ideas and expectations they have of one another.

Thus, the paper looks at cultural value in fishing, believing that this can make a contribution to better understanding small-scale fishing in Africa. ${ }^{1}$ To further develop this point, the paper now continues with an elaboration of the generic model of Nile perch fishing, showing how it resonates with a rational actor interpretation of human action. Next follows a discussion of the multi-method approach adopted for the data collection in this study, making use of a combination of anthropological fieldwork and survey work. The paper then moves to confronting the generic model with some field data. It shows that at national level there is a reasonable fit but that as one moves to the local level the fit becomes loose, or even incoherent. Detailed analysis of the economic histories of two adjacent landing sites points at the operation of different, spatially situated, fishing 
styles. In addition to an expressed preference for a particular fishing gear, these denote the social relations that Nile perch fishermen mobilise, the symbolic meanings they attach to gill nets and long-lines, and the values that inspires their fishing. Towards the end of the paper it will be shown how these styles habituate the fishermen's everyday lives, and thus have lasting implications for the spatial organisation of the Nile perch fishery.

\section{THE GENERIC MODEL OF NILE PERCH FISHING}

Work of leading social researchers on Lake Victoria's Nile perch fisheries is suggestive of a generic model that guides their study of Nile perch fishermen. It rests on three pillars: (i) migration to relatively rich fishing grounds; (ii) using catch-enhancing fishing technology; and (iii) straddling fishing with non-fishing activity. ${ }^{2}$ In more detail, the model looks something like this.

Because the availability of perch in Lake Victoria varies between locations and changes over time, fishermen are inclined to trek from one place to another once they see catches go down. Or, 'within Lake Victoria fisheries (...) geographical mobility is the most common response to low catches within an area' (Nunan 2010 , p. 783). Moving about the lake to places where Nile perch is more abundant is facilitated by a particular spatial organisation. In the wake of the Nile perch boom of the 1990s, many new landing sites were established around the lake. These function as a network of locations encompassing major trading hubs that are accessible via all-weather roads and smaller and often more remote landings accessible only by boat. Central to migrating fishermen's success in setting up a business elsewhere is whether they know other people who can facilitate their establishing a perch fishing business (Lwenya \& Yongo 2012). Hence the structure of perch fishermen's social networks shapes their spatial mobility.

In addition to moving to resource-richer areas, fishermen can increase their catches by extending their reach on the lake by using motorised rather than wind or muscle-based propulsion. Once fishermen have moved to using outboard engines, they will be inclined to invest in more (productive) fishing gear. This is thought to result from increased competition following from the popularity of perch fishing: 'With the increase in the number of fishers, catch and income has had to be shared between increasing numbers of boat owners and fishers, leading to an increasing effort through the use of more gears' (Nunan 2010, p. 779). With increasing gear use comes the mending of nets and lines, and in many landing sites the gear repairing industry has become sizeable, often employing less successful fishermen and/or presenting a labour reserve that can be mobilised if Nile perch catches are up (Medard 2012).

Once catches drop below a particular economic break-even point, fishermen tend to move from fishing into farming; they are pluriactive economic actors (Salmi 2005). A well-known thesis in this regard is that 'fishing and farming represent but two components of a survival strategy designed to ensure nutritional security' (Geheb \& Binns 1997, p. 91). Others likewise argue that: 'Farming is an important component of fishers' livelihood strategies on Lake Victoria (...) many involved in fisheries do farm as well, mostly on a subsistence level' (Nunan 2010, p. 781). At the same time, the fishermen maintain ties with their fishing (canoes are rarely sold off during meagre times), and, by thus straddling fishing and agriculture, fishermen can shield themselves from decline in one economic activity by moving capital and labour into another one that is more productive or dependable (Béné \& Merten 2008).

In sum: the generic model constructs Nile perch fishermen as risk hedging/taking, adaptive economic actors who make a wellconsidered choice from a palette of ecological realties handed to them by the lake and the landscape that surrounds it. The rational choice view on human action underpinning this model has been embraced in research and policy-making, but there are dissenting voices too. One early study in Tanzania, for instance, found that local Nile perch fishermen welcome outsiders, suggesting that they perceive competition in more inclusive terms than the generic model suggests; in the words of one of them: 'in fishing there is no segregation' (Wilson 1993, p. 28). Another observer noted that Nile perch 
fishermen's movements are seriously constrained by the high cash requirements of the fishing enterprise: boats and outboard engines are expensive items, excluding new entrants (Pringle 2005). Yet another contribution points at the significance of gender relations: the mobility of Nile perch fishermen may be more regulated by their social relations with women in different landing sites than by considerations of profit (Béné \& Merten 2008).

Because the controversy cannot be resolved in theoretical terms, it is now time to confront the generic model with empirical data. First a few words, however, about the data collection methodology.

\section{MULTI-METHOD RESEARCH METHODOLOGY}

Data collection for this paper was carried out during 12 months in central Uganda 20062009. It began with anthropological fieldwork in Lambu, a prominent landing site in Masaka district, where Nile perch fishing and trading prevail. In a preliminary round of field visits, major differences in the use of fishing gear were observed, as well as a major division of labour between the owners of the boats - local entrepreneurs investing in a business - and the crews working for them, as wage labourers. These social and technological differences were encountered in a small sample of six neighbouring landing sites that connect Lambu into Uganda's Nile perch export network (Figure 1). It was decided, therefore, to make them central to the research design.

Next, a local survey was carried out because preliminary interviews suggested an unexplained diversity in ethnic/migration origin, professional background, socio-economic status, and straddling with non-fishing activity for both boat owners and their crews. It comprised two survey projects. One was administered among boat owners $(n=51)$. A list of owners residing in the area was compiled with the help of several trusted informants.

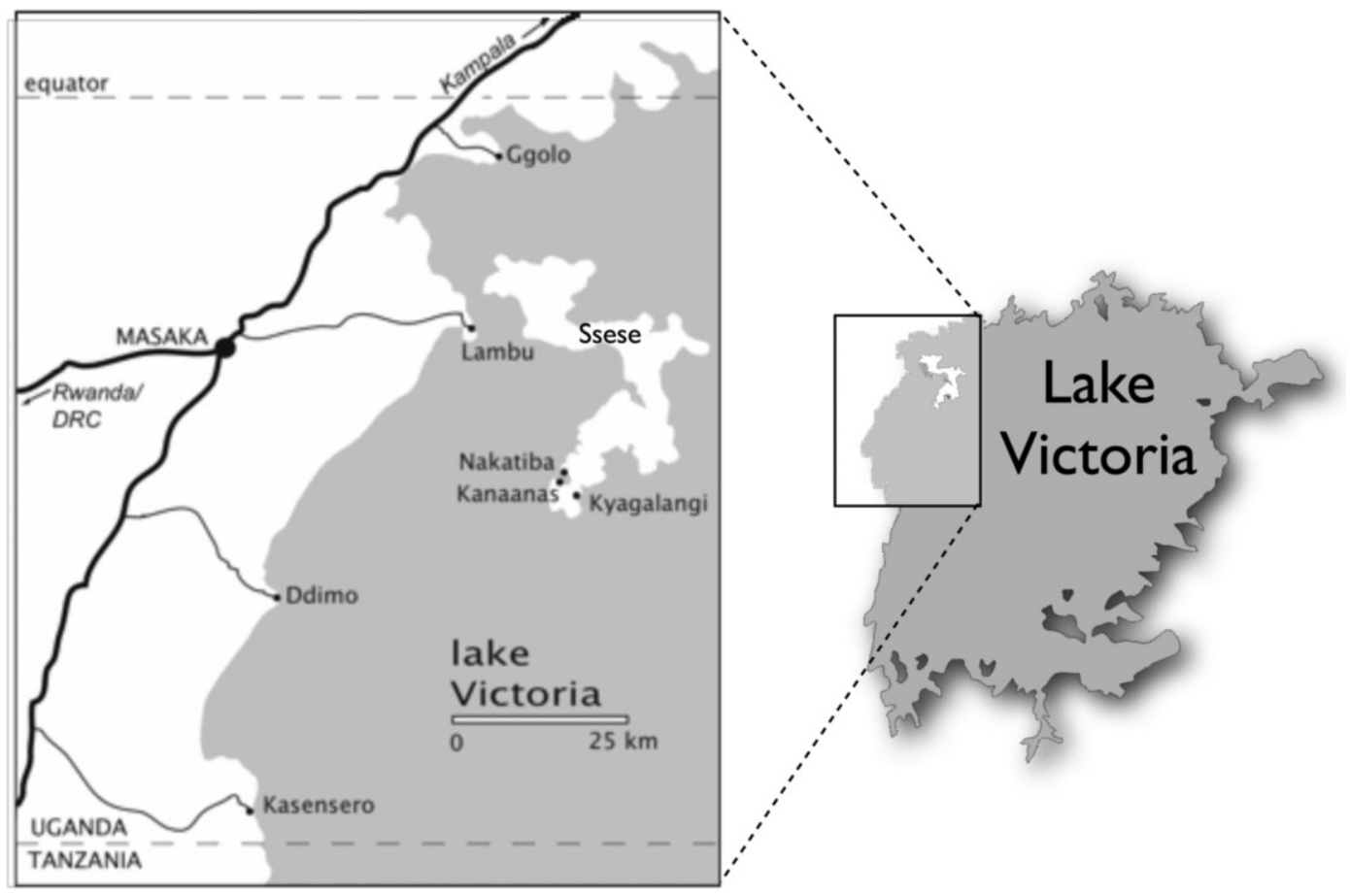

Source: Author.

Figure 1. Masaka district with selected landing sites. 
Table 1. Breakdown of sampled boat owners and crews over landing sites.

\begin{tabular}{lcr}
\hline Landing & Boat owners & Crews \\
\hline Ddimo & no data & 82 \\
Ggolo & 19 & 37 \\
Kasensero & 6 & 169 \\
Nakatiba & 7 & 92 \\
Kanaanas/Kyagalangi & no data & 96 \\
Lambu & 19 & 58 \\
Total & 51 & 534 \\
\hline
\end{tabular}

Source: Local survey (author).

Subsequently, structured interviews were conducted with the boat owners, and, with the aid of a research assistant, the results of these interviews were crosschecked with senior crewmembers. Another survey was carried out among the crews in the area $(n=534)$. Because there is no central register of fishing personnel in the area, it was decided to survey all crewmembers that were encountered in a particular landing site (Table 1 presents a breakdown of the informants). ${ }^{3}$

Then the research shifted to an examination of frame survey data on the Ugandan part of Lake Victoria (LVFO 2004; GoU 2006, 2008). To allow comparison with the field data (the local survey including), frame survey material was studied for the post-2006 period. Conducted biannually by East African Community fisheries experts, the frame survey collects representative data about the number of fishermen, boat type, mode of propulsion, and fishing gear. Thus it provides an interesting dataset to contrast the findings of the local survey. Though a systematic comparison is not the within the scope of this paper (complicated also by methodological differences), the comparison pointed at spatial differences, in particular with regards resource endowment, use of fishing gear and boat owners' length of residence.

To understand these differences better, the research returned to the local level to reconstruct the socio-economic histories of the sampled landing sites. This was done because historical processes were found to shape spatial differences. For the purpose of comparison and looking for empirical contrast, in addition to Lambu, the landing site of Ggolo was selected for further analysis. Their histories

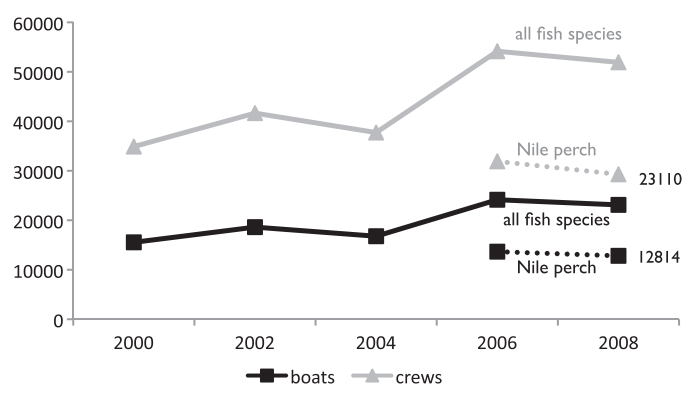

Note: Nile perch data not available before 2006. Sources: LVFO (2004), GoU (2006, 2008).

Figure 2. Boats and crews 2000-2008.

were reconstructed in a round of additional interviews, and making use of satellite imagery and photographs.

\section{UGANDA AND MASAKA DISTRICT: THE GENERIC MODEL APPLIED}

Uganda - Examination of the responses of Nile perch fishermen in Uganda as they appear from the frame survey data reveals three major trends. Trend 1: The number of boats used for Nile perch fishing as well the number of fishermen working on them declined after 2006 (Figure 2). ${ }^{4}$ The decline follows the significant dip of about 50 per cent in Nile perch exports which Uganda (and other riparian countries) saw after 2006, but is perhaps less than could be expected from the magnitude of the dip. The difference is explained by fishermen's adaptations that remained under the radar of the frame survey. For instance, sources report that catches per boat dropped (Balirwa 2007), and presumably fishermen took their losses. Further, the crews working on the fishing boats faced longer spells of unemployment. Although systematic data for crews are scant, observations in the research area suggest that crews responded to this by settling for part-time work and by spending more time in between jobs (Beuving 2010). The frame survey does not record movement between fisheries, but fishing for mukene (a sardine-type fish requiring little capital investment that is used for local fodder and food production) continued to thrive, suggesting that Nile perch fishermen moved to another fishery (Awange \& Ong'ang'a 2006). 
Table 2. Gear type and propulsion, 2008 (Nile perch).

\begin{tabular}{|c|c|c|c|c|}
\hline \multirow[t]{2}{*}{ Propulsion } & \multirow{2}{*}{$\frac{\text { Boats }}{\text { Number }}$} & \multicolumn{3}{|c|}{ Gear breakdown } \\
\hline & & Gill nets & Long-lines & Other \\
\hline Outboard engine & 5,293 & 0.70 & 0.29 & 0.01 \\
\hline Paddle & 6,491 & 0.27 & 0.50 & 0.23 \\
\hline Sail & 1,029 & 0.26 & 0.72 & 0.02 \\
\hline Total & 12,814 & 0.45 & 0.43 & 0.12 \\
\hline Comparison: 2006 & 13,657 & 0.51 & 0.39 & 0.10 \\
\hline
\end{tabular}

Sources: LVFO (2004); GoU (2006, 2008).

Table 3. Gear in LV fisheries, 1975-2008 (all fish species).

\begin{tabular}{|c|c|c|c|c|c|}
\hline \multirow[t]{2}{*}{ Year } & \multirow[t]{2}{*}{ Phase } & \multirow{2}{*}{$\frac{\text { Boats }}{\text { Number }}$} & \multicolumn{3}{|c|}{ Gear breakdown } \\
\hline & & & Gill nets & Long-lines & Other \\
\hline 1975 & Pre-boom & 2,760 & 0.66 & 0.10 & 0.24 \\
\hline 1989 & Start boom & 8,674 & 0.68 & 0.08 & 0.24 \\
\hline 2002 & Boom & 18,612 & 0.47 & 0.28 & 0.25 \\
\hline 2008 & Post-boom & 23,110 & 0.40 & 0.31 & 0.29 \\
\hline
\end{tabular}

Sources: Butcher and Colaris (1975); Coenen \& Tumwebaze (1991); Sedawog (1999); LVFO (2004); GoU (2006, 2008).

Trend 2: There is a move away from using gill nets to using long-lines (Table 2). The shift to long-lines (from $39 \%$ to $43 \%$ of the boats) is more general to fishing on Lake Victoria: whereas in 1975 only 10 per cent of the boats were fitted with long-lines, this figure had almost tripled in 2008 (Table 3). Despite its current popularity, fishing with long-lines preceded the perch boom, but it was abandoned in the wake of the civil unrest in Uganda during the 1980s when successive administrations prohibited long-line fishing on the ground that this was practiced at night and could therefore not easily be monitored (Reynolds \& Ssali 1990). Thus, at the onset of the perch boom in the 1980s, fishermen around the Ugandan part of the lake were habituated to using nets, and continued to do so at first. The use of long-lines fitted with hooks appears to have been reintroduced by migrant fishermen from Kenya in the late 1990s, and they have been adopted with great enthusiasm since. Interviews suggest that this is related to the lower initial costs of longlines versus nets: gill nets are imported goods, bought in shops in town and cost a few hundred euro per pair, whereas long-lines are manufactured locally, costing 10 to 15 euro. ${ }^{5}$

Trend 3: Fishermen migrate to resourcericher landing sites in response to changes in the availability of Nile perch. This trend may be broken down into two sub-trends. First, Figure 3 suggests that, between 2006 and 2008, fewer boats were recorded at very large and at very small landings, and that more boats moored at intermediate landings ( $20-50$ boats). Interviews suggest that fishermen regard very large landings as 'overcrowded,' a way of expressing competition, and that they regard opportunities to establish new and profitable business here as limited. Very small landing sites, on the other hand, are generally not well connected to the hinterland, thus adding to the cost of transporting the fish to markets further afield. Second, the percentage of Nile perch boats recorded in the Ssese islands increased from 15.2 per cent to 17.5 per cent between 2006 and 2008, suggesting that the frontier of fishing is shifting from the lakeshore to locations on the lake. ${ }^{6}$

In sum, these points subscribe to the image of the adaptive, risk-minimising fisherman 


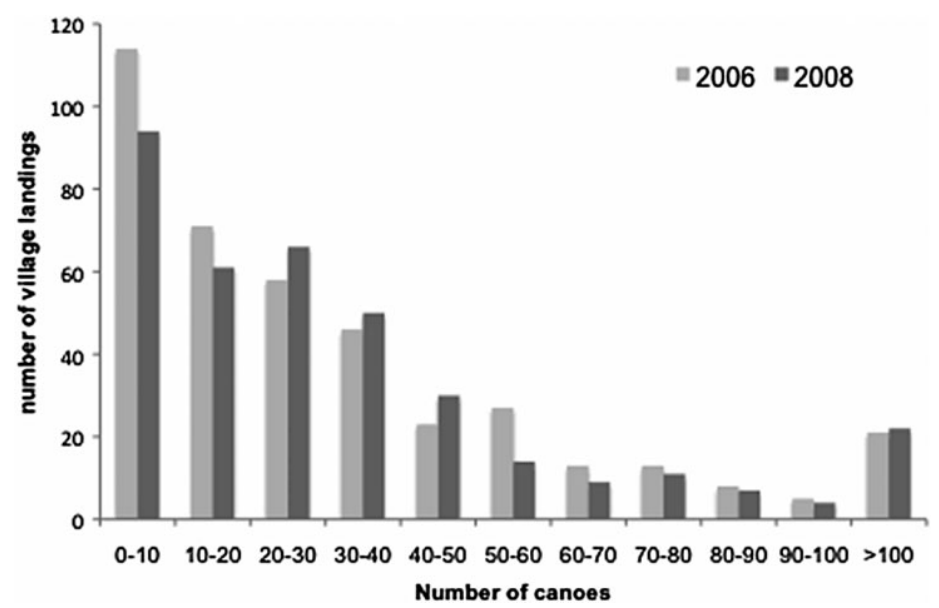

Sources: GoU (2006, 2008).

Figure 3. Boats recorded in villages landings, 2006 and 2008.

Table 4. Average fleet size per boat owner category, 2007 and 2009.

\begin{tabular}{lrrrrr}
\hline Boat owner $(\mathrm{n})$ & \multicolumn{2}{c}{2007} & & \multicolumn{2}{c}{2009} \\
\cline { 2 - 3 } & Owned & In use & & Owned & In use \\
\hline Large $>5(6)$ & 12.4 & 12.4 & & 12.3 & 8.8 \\
Medium: 2-5 (21) & 2.2 & 2.2 & & 2.1 & 2.0 \\
Small $<2(23)$ & 1.0 & 1.0 & 1.0 & 1.0 \\
Average (51) & 144.0 & 144.0 & 141.0 & 118.0 \\
\hline
\end{tabular}

Source: Local survey (author).

discussed earlier: there are fewer fishermen, the fishermen are moving further onto the lake, and they rely on less capital-intensive types of fishing gear - these can be seen as responses to operating under increasingly competitive and risky conditions. Thus we see here the generic model in action at national level. The paper now turns to an exploration of how this works on a small section of the Ugandan part of the lake.

Masaka district - In the research area, fishermen usually make a distinction between largerand smaller-scale boat owners. ${ }^{7}$ Boat ownership is skewed in the area. The local survey suggests that 12 per cent of boat owners own more than five boats, 42 per cent own between two and five boats, and 46 per cent own only one or two boats (Table 4). Larger owners tend to continue owning many boats, but they make regular use of fewer vessels than they did previously. This corroborates a major observation during the fieldwork: many boats were beached, some of them under repair, but most sitting there idly (hence the table distinguishes between 'owned' and 'in use'). ${ }^{8}$ Medium to smaller owners continue to fish perch using more or less the same number of boats. Thus, although there was an overall reduction of approximately 30 per cent in the total number of boats used, this pertains mainly to larger boat owners. For those operating several boats, it is worthwhile to temporarily reduce their fleet and wait for better times, whereas for smaller owners, who own only a few boats, shedding risk by reducing their fleet would mean exiting fishing.

Larger owners tend to own more land, use more land for cash cropping (notably coffee), and have more cattle at their disposal 
Table 5. Land and cattle per boat owner category, 2009.

\begin{tabular}{lcccc}
\hline Boat owner $(\mathrm{n})$ & \multicolumn{3}{c}{ Landholding (acre) } & Cattle \\
\cline { 2 - 4 } & Total & Cash crop & Subsistence & Heads \\
\hline Large $>5(6)$ & 10.7 & 5.0 & 4.8 & 5.8 \\
Medium: 2-5 (21) & 4.1 & 0.8 & 1.6 & 1.3 \\
Small $<2(23)$ & 1.8 & 0.5 & 1.0 & 0.3 \\
Average (51) & 3.7 & 1.2 & 1.8 & 1.3 \\
\hline
\end{tabular}

Source: Local survey (author).

Table 6. Key characteristics boat owners, 2008/9.

\begin{tabular}{|c|c|c|c|c|c|c|c|c|}
\hline \multirow{3}{*}{ Landing (n) } & \multicolumn{2}{|r|}{ Bio } & \multicolumn{3}{|c|}{ Agriculture } & \multicolumn{3}{|c|}{ Fishing } \\
\hline & \multirow{2}{*}{$\frac{\text { Age }}{\text { Years }}$} & \multirow{2}{*}{$\frac{\text { Residence }}{\text { Years }}$} & \multicolumn{2}{|c|}{ Landholding (acre) } & \multirow{2}{*}{$\frac{\text { Cattle }}{\text { Heads }}$} & \multirow{2}{*}{$\frac{\text { Boats }}{\text { Number }}$} & \multicolumn{2}{|c|}{ Gear breakdown } \\
\hline & & & Total & Cash crop & & & Gill nets & Long-lines \\
\hline Gollo (19) & 36.9 & 35.1 & 10.7 & 5.0 & 5.8 & 3.1 & 0.57 & 0.43 \\
\hline Kasensero (6) & 35.1 & 33.5 & 4.1 & 0.8 & 1.3 & 6.8 & 0.63 & 0.37 \\
\hline Nakatiba (7) & 41.2 & 8.4 & 1.8 & 0.5 & 0.3 & 2.2 & 0.26 & 0.74 \\
\hline Lambu (19) & 36.7 & 9.5 & 1.7 & 0.2 & 0.3 & 1.3 & 0.15 & 0.85 \\
\hline Average (51) & 37.5 & 26.4 & 3.7 & 1.2 & 1.3 & 2.7 & 0.34 & 0.66 \\
\hline
\end{tabular}

Source: Local survey (author).

(Table 5). ${ }^{9}$ Further, interviews with individual landowners indicate that those with more than four or five acres are usually boat owners originating from landing sites, or with close ties there, often in the sphere of kinship relations, whereas smaller boat owners tend to be migrants with some outside cash who came to the lakeshore in order to establish a perch business. In addition to their landholdings being smaller than those of larger owners, the land of smaller boat owners is usually located further afield, typically not far from where they migrated. This presents them with the special problem of supervising land use at a distance. Many of the smaller boat owners, unable to supervise their land directly, are reluctant to make the necessary investment in it. As one starting boat owner remarked: 'I never send money home; they will not buy fertiliser and put it on the crop, but squander it in town' ${ }^{10}$ As a consequence, the mobile telephone shop in Lambu specialising in remitting money via cell phone closed down after only a few months in operation. Its operator explained to me that
'These fishermen, they spend their cash here, or they keep it in their pocket; there is therefore not enough business for me to continue'.

If these resource endowment differences are considered spatially, a pattern begins to emerge: it shows that there are 'richer' and 'poorer' landing sites in the area. Table 6, for instance, shows that, whereas boat owners from Ggolo and Kasensero generally have abundant land, own from three to almost seven boats on average, and predominantly use gill nets, boat owners from Lambu and Nakatiba have far smaller landholdings, they own only 1.3 boats on average, and rely mainly on long-lines for perch fishing. Local wealth differences correspond to differences in the boat owners' length of residence. Whereas Ggolo and Kasensero boat owners have lived most of their lives in these landing sites, those encountered in Lambu and Nakatiba had lived there only a few years. This suggests that the former may be characterised as residential boat owners, whereas among the latter there is a high proportion of migrants. There are several 


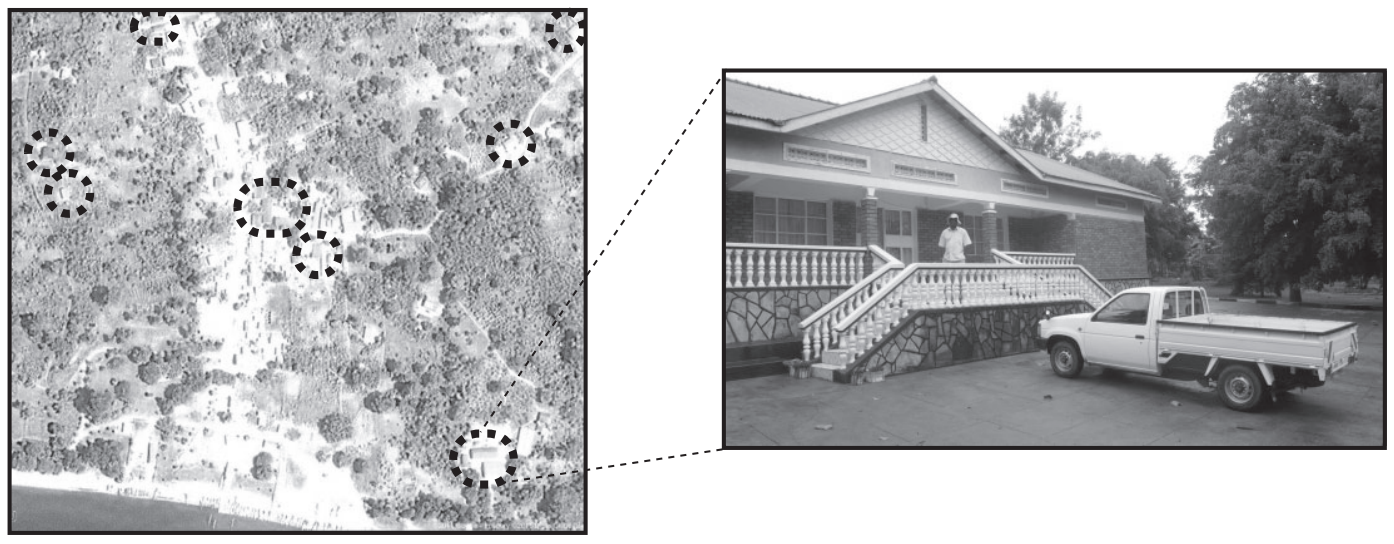

Source: Google.Maps (processed by author) and personal archive author.

Figure 4. Luxuriously roofed houses in Ggolo (left), with wealthy boat owner in front of one of them (right).

socio-economic and historical reasons shaping these differences, a point to which the paper now turns.

\section{COMPARING THE LANDING SITES OF GGOLO AND LAMBU}

The landing sites of Ggolo and Lambu in many ways represent the diversity in fishing practices, social hierarchies, and embedding in alternative economic activity recorded during the field research. Its material outcome - 'richer' and 'poorer' landings - can be readily observed. In this part of Africa, the state of housing is usually seen as a reliable indicator of capital accumulation, and roofing is a key aspect: wealthy house owners tend to use luxury roofing such as coated iron sheets or even tiles, whereas poorer ones use plain sheet iron. Looked at from above, different roofing can therefore be distinguished on the basis of colouration. Recent satellite imagery of the research area, for instance, shows that the residential area in and around Ggolo is dotted with greenish roofs, corresponding to expensive houses constructed by successful boat owners (Figure 4). The residential area in Lambu, on the other hand, shows greyish dots, an indication of the common roofing used in house construction there (Figure 5).

The paper now tries to relate these observations to the socio-economic histories of both landing sites and to cultural valuations of fishing technologies relating thereto.

Ggolo and Lambu: socio-economic histories Ggolo is locally known as a 'traditional' fishing village. It is home to a thriving community of ethnic Baganda fishermen and farmers, hosting several lineage shrines - a sure sign that people have been living here for a considerable time. Fishing has been practiced here for as long as older residents can remember; and by trading fish with the hinterland - notably to the nearby town of Masaka - but also by selling cash crops such as coffee, Ggolo has a long history of integration with the regional economy. Through this integration, many Ggolo residents profited from the vibrant informal/ illegal trade that dominated Uganda's highly regulated economy during the 1970s and 1980 s, resulting from shortages of essential commodities that followed from economic controls pursued by the Amin and Obote administrations (Himbara \& Sultan 1995). Called magendo, several landowning fishermen (and their families) made healthy profits from this trade, which was invested in early purchases of outboard engines and in high-quality boats made of hardwood, essential to increase the reach and speed of their magendo networks, stretching along Uganda's coast.

After the magendo era ended as a consequence of economic deregulation by the 


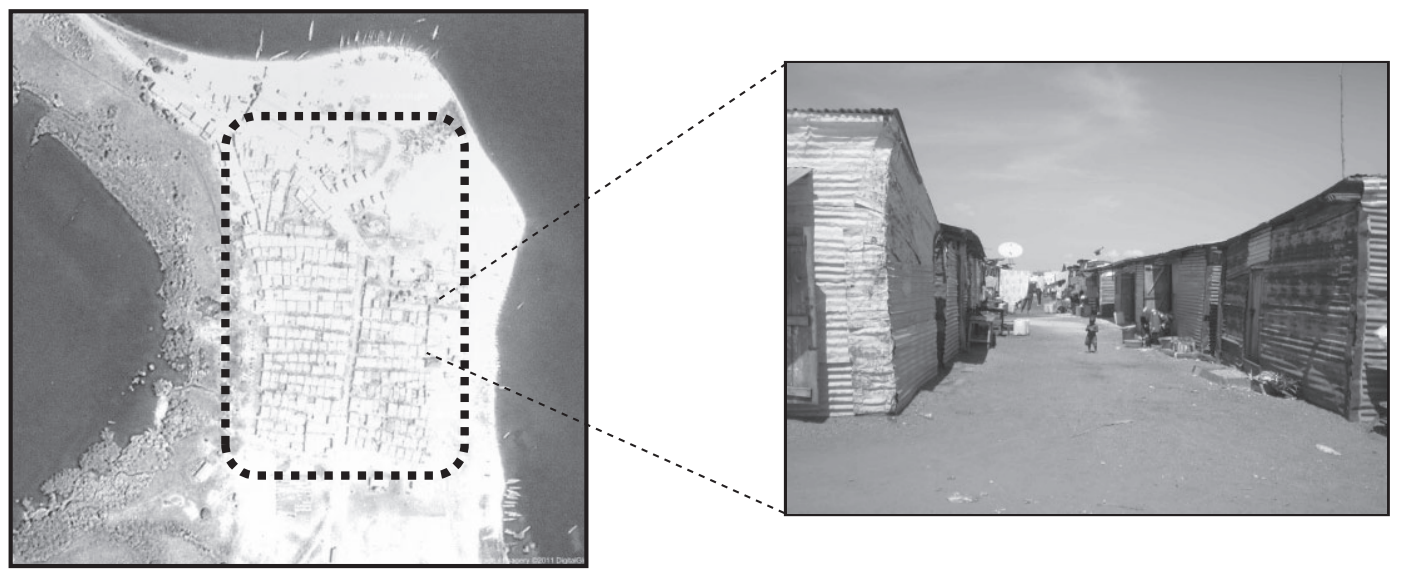

Source: Google.Maps (processed by author) and personal archive author.

Figure 5. Simple roofed houses in Lambu (left), with a view in a main street (right).

Museveni administration in the late 1980s, Ggolo businessmen were equipped with strong boats, powerful outboard engines, and capital to spare. Several of them had established themselves in the area around Kasensero, a crucial hub in the magendo trade, and, when a factory processing Nile perch was constructed here in 1994, they were among the first fishermen to move into perch fishing, mainly by using nets as was customary in those days. With the money they thus made, more land could be purchased in the fertile Ggolo area, and some started building (and beautifying) houses there too. During the early stages of the perch export boom (the mid-1990s), more fishermen from Ggolo followed, mostly relatives of those already established. Consequently, today many of the larger boat owners operating in the research area originate from this particular landing site, and the local survey suggests that about 45 per cent of all the boats recorded in the area are owned by Ggolo fishermen. With declining perch catches, many of them have diversified into other economic activities, cash crops being an obvious choice; and some too have moved into poultry rearing, which is viewed as a prospering business because of export opportunities to South Sudan.

Lambu is an example of the new landing sites that emerged in the wake of the expanding perch export (like the majority of Uganda's landings today). It gained some prominence during the colonial era when the British identified it as a strategic place for trade and established a port there - one of a series of smaller ports used to operate ferries across Lake Victoria up to Bukoba and Mwanza in presentday Tanzania. Later, the district commissioner selected a small hilltop directly behind Lambu known for its beautiful view over the lake to construct a holiday home - the building is still there today. Thus Lambu figured in colonial administrative and trade circles, but it was also a stopping place for local fishermen moving up and down the lakeshore. However, with the rise of Lake Victoria's water level throughout the 1960s, Lambu was cut off from the mainland and became an island. The British subsequently closed the port and abandoned the island eventually. For a while, Lambu continued to function as a resting place for visiting fishermen, but no permanent settlements were seen in those days. This situation changed again when the water level dropped in the 1980 s, reconnecting Lambu with the mainland.

Around this time, trade with the nearby Ssese islands was picking up. These islands were uninhabited for most of the twentieth century because of persistent problems with trypanosomiasis causing sleeping sickness, and people did not resettle there in numbers sufficiently large to support trade until around the 1980s. When this happened, Lambu's beaches were strategically positioned as a point of departure, 
attracting growing numbers of traders, but also some fishermen (there are few farmers: land is scarce because Lambu is surrounded by a swamp area, making it unsuitable for growing crops). Many were attracted by the fact that the waters close to Lambu in those days teemed with silverfish. Lambu's population gradually expanded as a result, but this expansion accelerated from the mid-1990s onwards when 'new' fishermen settled down, typically coming from rural places across the country, lured by the prospect of making money from Nile perch. Today, a sizeable but floating community of perch fishermen exists in Lambu, many of them alternating their stay there with fishing trips from nearby landing sites on the Ssese islands.

The cultural meaning of fishing gear - Whereas Ggolo developed into a centre for net fishing, Lambu gained a local reputation as port mukonyo. These differences in fishing-gear orientation reflect to some extent a difference in capital concentration. As indicated, nets are expensive to buy (and prone to theft or damage), but they have the advantage that costs per fishing trip are low because no additional inputs are required. The reverse pertains to long-line fishing because it requires the use of live bait. The bait comprises either muddwelling cichlids from Lake Victoria, locally called nkejje, or, less commonly, infant mudfish from nearby lakes and rivers, called nsonzi. Whereas long-lining fishermen in the past collected their own bait, with the growing popularity of this fishing method, specialised traders moved into the collection and commercialisation of the baitfish. Today, perch fishermen using long-lines buy most of their bait from such traders, and the growing popularity of long-line fishing has meant rising prices for this key input. Although prices vary depending on bait availability, interviews with several mukonyo fishermen indicate that they typically spend 35-50 euro per trip on the baitfish.

Using either type of fishing gear has consequences for catches. Whereas a fisherman using nets will almost always return to port with some fish - either perch or a saleable by-catch such as tilapia - the long-line fisherman in Lambu and its environs often returns emptyhanded. However, this mode of fishing is also associated with bumper catches, even though this increasingly seems to be a thing of the past with declining perch stocks. In daily practice, this means that the financial risks involved in long-line fishing are much higher than those involved in using nets: initial costs may be low (hence the attraction to growing numbers of fishermen), but variable costs are much higher, and they are not automatically offset against higher or more dependable catches. So rather than moving into low-risk fishing because of insufficient capital, perch fishing in the mukonyo type of landing sites such as Lambu entails a move into higher-risk forms of activity.

But local meanings of fishing technology go beyond a mere assessment in terms of costs and catches. Well-established butimba fishermen tend to disregard mukonyo fishermen and rather not to be associated with them. One boat owner from Ggolo once remarked: 'What they do is not fishing; those mukonyo fishermen are just adventurers!' Another one in Kasensero once stated a broadly shared opinion, claiming that 'Using hooks [long-lines] is for poor fishermen; those with money fish with nets'. A third one made the following remark: 'It's like this. Fishing with nets is like having a wife: if you stay with her, you can keep your money in the pocket, and people will think well of you. If you fish with hooks, it's the same as going to prostitutes all the time: at the end you have no money left and people make fun of you!' Confronted with such stereotypes, aspiring businessmen wishing to venture into perch fishing, but lacking sufficient means to purchase the necessary gear, are not likely to start their enterprise from Ggolo. They cannot, therefore, easily get access to the better-capitalised Ggolo business networks that can promote a move into the more prestigious butimba fishing (banks are reluctant to issue loans to starting fishermen). Thus, whether one fishes butimba or mukonyo is determined by the interlocking of local social hierarchies, the prestige of using a particular type of fishing gear, and access to business contacts.

\section{ANALYSIS: SOCIO-GULTURAL DIVERSITY IN NILE PERCH FISHING}

The histories of Lambu and Ggolo suggest that choosing butimba or mukonyo is part of a spatially 
situated style in Nile perch fishing: the first one revolving around low-capital-intensity fishing with long-lines, attracting migrant fishermen who have settled recently and operate one or two boats; and the second one revolving around high-capital-intensity fishing with gill nets by residential fishermen who have been fishing for most of their lives and operate several boats. The material further suggests that socio-cultural forces drive these distinctions, a point to which the paper now turns.

The degree to which a fisherman can mobilise personal contacts constitutes a key asset in Nile perch fishing. In the limited presence of formal institutions such as banks or government services, many perch fishermen depend on their social contacts for mobilising key resources, notably capital, but also for setting up business in a new location where perch catches seem promising. Knowing other people in the business, and being able to make use of one's 'trans-lake' social network, therefore represent an important asset. The material suggests that this is promoted by length of stay. Dependable social contacts take time to develop, and individuals born and raised close to the lake therefore have a potential edge over those coming from afar, materialising in successful and less successful perch fishermen, respectively. A distinction between migrant and more residential perch fishermen therefore constitutes a useful beginning in understanding the spatial organisation of fishing practices.

This social distinction seems to be tied up with the economic histories of landing sites. In older landing sites, fishermen are socialised into a broad network of potential collaborators, to which they can turn for assistance; likewise, in landings where migrants prevail, a more ephemeral social universe is found with less build-up of dependable social ties. This research suggests a relation with economic endowment: in villages with an established history of fishing, social relations are better developed, and these can be converted into economic forms of capital, resulting in concentration of productive resources. This dynamic of social relations helps to explain why many of today's wealthier landing sites belong to the minority category of about 15 per cent of landings that existed well before the Nile perch boom took off in the late 1980s (Heck et al. 2004). But there is variation in this broad trend too. For instance, several pre-boom landing sites have disappeared from the official record, suggesting that fishermen ceased to land Nile perch there, and others have lost their significance in the perch export network. In other words, there is a more complex dynamic at work here, and careful study of economic histories of locations around Lake Victoria may give more profound insight into the spatial patterning of resource endowment.

One possible explanation for the less-thanstraightforward relation between the economic history of a landing sites and the degree to which it succeeds in benefiting from the perch boom may be found in the way culture operates. The findings presented earlier suggest that culture shapes fishermen's preference for a particular type of fishing gear. Conventional explanations view this choice as grounded in biological characteristics of the resource itself, or in differences in the cost of purchasing and operating particular fishing gear (Platteau 1989). This research does not contradict the idea that considerations such as hunting the fish efficiently, or reducing money spent on fishing trips, feature prominently in the minds of individual perch fishermen. However, it appeared also that choosing to use long-lines or gill nets is valued in different ways, and this has consequences for how it is socially sanctioned. An aspiring fisherman who wants to start a career in perch fishing, say in Lambu, will choose long-lines not only because they are cheaper to fabricate than buying a set of imported nets, but also because his friends and colleagues will expect him to do so. Such expectations can be highly localised, as the discussion on Ggolo and Lambu suggests, because they are generated in spatially situated fishing networks.

However, the significance of culture exceeds the issue of how expectations govern the choice of a particular fishing technology. It also works on the decisions of individual fishermen to venture into fishing Nile perch. Residential fishermen are socialised into established fishing networks, and, when the opportunity to diversify or expand into commercial perch fishing presented itself in the 1990s, for those engaged in these networks it seemed an obvious course of action. New entrants, 
currently constituting the majority of perch fishermen, are driven by a different expectation. They have often come from elsewhere, and they have more deliberately opted for this mode of commercial fishing, to a significant extent because there is a prospect of making money. Many new entrants therefore move into perch fishing expecting to make a handsome profit. They settle in a particular landing site, usually one where they have a minimum set of social contacts on which to build, and these are often migrants too. Their financial stakes are higher, because they bring outside capital to invest this in a boat, outboard engine, and fishing gear, or, in the case of fishing crews, they must have some cash in hand to tide themselves over the time it takes to secure a paid position. Local stories about bumper catches common in the heyday of the boom but now increasingly rare due to shrinking fish stocks and increased competition - fuel their expectations.

These reflections suggest that the emergence of different fishing styles has lasting consequences for the organisation of the Nile perch fishing. Butimba fishing is associated with the use of gill nets by mono-ethnic, residential fishermen for whom perch fishing presented an obvious choice. Mukonyo fishing is connected with long-line fishing by poly-ethnic, migrant fishermen (including fishing crews) who arrived at a later stage in the perch boom, driven by the expectation of making money. It further suggests that different fishing styles coagulated into spatial patterns as follows:

- butimba fishermen build more on kinship networks, promoting circular migration and their using a larger part of the lake; with mukonyo, migration depends more on nonkin ties, contributing to more localised migration practices;

- economic and social barriers for entry to butimba are high so that its spread tends to follow established fishing networks; such barriers are lower for mukonyo fishermen and their prevalence is more determined by prevailing market conditions;

- butimba fishermen have a lower expectation of immediate returns, they are more inclined to look for alternative economic activity; the frontier of their fishing depends on non- fishing considerations. Mukonyo fishermen identify more with making money through fishing only; its spread therefore depends more on fish resource dynamics.

That two different fishing styles were found in adjacent locations is salient in view of the expansiveness of Lake Victoria, but to claim its place in a broader discussion about spatial diversity, this finding has to be contextualised. Whether it represents an outlier or a structural aspect of the Nile perch sector is a matter that has to be resolved empirically in future research. Moreover, identifying different styles is to some extent an abstraction because it does not mean that there are no social ties between those associated with each style. Even a brief visit to a landing site shows that large-scale boat owners, small-scale Nile perch fishermen, and fishing crews frequently and routinely interact socially. A quick conversation with a Nile perch fisherman, be it a well-established veteran, a senior crewman, or a freshly arrived new entrant, shows that many of those living in landing sites are aware of one another's whereabouts - even though they draw on different socio-economic backgrounds. In other words, reifying these styles in day-to-day interaction is not helpful in understanding the different responses of individual Nile perch fishermen. Nonetheless, it directs attention to social practices in fishing and that can help to move beyond a narrow interpretation of small-scale fishing emphasising rational action that is of limited help in grasping complex empirical realities on Lake Victoria.

\section{CONGLUSION}

The spatial diversity observed in this study directs attention to socio-cultural factors in small-scale fishing in Africa. A widely adopted generic model developed for the lake as a whole proved of limited use in interpreting the diverse responses of small-scale fishermen to the highly dynamic Nile perch sector. That is because it emphasises rational action in fishing, at the cost of a limited attention for differences in fishing styles. Such styles, it was found, foster small-scale fishermen's socialisation in particular social networks, their using different gears, and the expectations they carry into the fishing 
business, thus impacting on the spatial organisation of fishing. The paper does not offer a final statement about this, but hopes to invite further research that begins with an interest in actual social practice.

\section{Acknowledgments}

The author thanks the Wenner-Gren Foundation for funding the fieldwork; the Makerere Institute for Social Research and the Ugandan National Council for Science and Technology for institutional support; and Jens Andersson, Jan Kees van Donge, Tessel Jonquière, John Kinsman, Leo Nagelkerke, Paul van Zwieten, and two anonymous reviewers for their insightful comments. Catherine O'Dea is thanked for language editing.

\section{Notes}

1. Culture in the sense implied here looks at actors' shared interpretations of social behaviour, believing that such interpretations in their turn shape the behaviour of actors (Geertz 1993. Applied to small-scale fisheries research, it has the advantage that it looks at situational aspects of fishing, without making a priori assumptions about the social organisation of fishing, and therefore seems to apply well to the selected case (compare Béné \& Tewfik 2001; McCormack 2010).

2. To fully appreciate its place in the article, please note that (i) it is a conceptual model that makes no predictive claims in the sense that a formal, mathematical model can, and (ii) it is a composite of what various leading researchers have put forward over the years. Thus the generic model presented here functions as heuristic device seeking to contribute to the academic debate about spatial diversity in small-scale fishing.

3. Because the researcher is not fluent in the local language (Luganda), and few boat owners/ crews speak English well, use was made of research assistants. Three were recruited: two were educated men from outside the research area and one came from within. The insider, a crewmember, was important in smoothing access to the boat owners and crews, some of whom confused our presence with that of Fisheries Department staff looking for law-breakers. All received on-the-job training and were supervised by the researcher.
4. Data for Nile perch were available only for 2006 and 2008, but they roughly follow trends in boats and fishing crews for all major commercial fish species, notably tilapia and silverfish.

5. Note that in the area, the same boats are used for long-line and gill net fishing: a standardised class of vessels built from wooden planks and approximately 9 metres in length, and propelled usually by a $9.9 \mathrm{hp}$ outboard engine. These boats, manned by a three-person crew, carry up to six gill nets or several hundreds of metres of longlines/hooks.

6. The Ssese islands are an archipelago in Lake Victoria off the coast of Masaka district reputed for high catches. Total boat numbers decreased during this period from 13,675 to 12,814 .

7. These large boat owners work with large crews, overseen usually by senior crewmen, whereas small boat owners work with smaller crews. In neither case is there a habituation of work relations (kinship ties are rare) and conflicts over pay and profit are frequent. Crews are not inclined, therefore to migrate with boat owners.

8. Taking boats out of service quickly reduces their value because the wooden planks from which they are made quickly develop cracks, and the caulk sealing the seams between the planks crumbles. At the same time, prices for used boats usually drop if catches go down because of reduced demand, resulting in a 'catch-22' situation with limited possibilities to recoup cash invested in boats.

9. Land ownership in Uganda is complicated because it entails a range of ownership/use practices. The most common form, kibanja, refers to a long-term lease, but those cropping kibanja fields tend to regard themselves as the rightful owners. Registered land presents the apex of the ownership hierarchy, but in practice this is reserved for wealthy persons capable of processing costly land registration procedures. For practical purposes, the survey makes no distinction between kibanja and registered land.

10. Similar remarks were recorded among crews. They do not resolve this problem by travelling to and fro. The local survey shows that, outside Christian and Muslim holidays, few travel back to their home village. Interviews suggest that this is related to the cost of transport, which can easily equate to several days' revenue. 


\section{REFERENCES}

Appleton, J. (2000), 'At My Age I Should Be Sitting Under That Tree': The Impact of AIDS on Tanzanian Lakeshore Communities, Gender E Development 8, pp. 19-27.

Awange, J. \& O. Ong'Ang'A, (2006), Lake Victoria. Ecology, Resources, Environment. Amsterdam: Springer.

BAlirwa, J. (2007), Ecological, Environmental and Socioeconomic Aspects of the Lake Victoria's Introduced Nile Perch Fishery in Relation to the Native Fisheries and the Species Culture Potential: Lessons to Learn. African Journal of Ecology 45, pp.120-129.

Béné, C. \& A. Tewfik (2001), Fishing Effort Allocation and Fishermen's Decision-making Process in a Multi-species Small-scale Fishery: Analysis of the Conch and Lobster Fishery in Turks and Caicos Islands. Human Ecology 29, pp. 157-186.

Béné, C. \& S. Merten (2008), Women and Fish-forsex: Transactional Sex, HIV/AIDS and Gender in African Fisheries. World Development 36, pp. 875899.

Beuving, J. (2010), Playing Pool Along the Shores of Lake Victoria. Fishermen, Careers and Capital Accumulation in the Ugandan Nile Perch Business. Africa 80, pp. 224-248.

Beuving, J. (2013), Chequered Fortunes in Global Exports: The Sociogenesis of African Entrepreneurship in the Nile Perch Business at Lake Victoria, Uganda. European Journal of Development research 25, pp. 501-517.

Butcher, C. \& M. Colaris (1975), A Sociological Survey of the Fishermen Population around Lake Victoria. Rome: FAO.

Coenen, E. \& R. Tumwebaze (1991), Report on the Frame Survey Conducted in the Ugandan Part of Lake Victoria. Rome: FAO.

Dijkstra, G. \& J.-K. van Donge (2001), What Does the 'Show Case' Show? Evidence of and Lessons from Adjustment in Uganda. World Development 29, pp. 841-863.

GeErtz, C. (1993) The Interpretation of Cultures, New York: Basic Books.

Geneb, K. \& T. Binns (1997), 'Fishing Farmers' or 'Farming fishermen'? The Quest for Household Income and Nutritional Security on the Kenyan Shores of Lake Victoria. African Affairs 96, pp. 73-93.

Government of Uganda (GoU) (2006) Frame Survey 2006: Data Districts by Fish Landing Sites and
Boats. Kampala: Ministry of Agriculture, Animal Industry and Fisheries.

Government of Uganda (GoU) (2008) Frame Survey 2008: Data Districts by Fish Landing Sites and Boats. Kampala: Ministry of Agriculture, Animal Industry and Fisheries.

Hara, M. \& E. Jul-Larsen (2003), The 'Lords' of Malombe: An Analysis of Fishery Development and Changes in Fishing Effort on Lake Malombe, Malawi. In: E. Jul-LARSEN, L. Kolding, R. OverÅ, J. RaAkJÆr, N. Nielsen \& P.A.M. van Zwieten, eds., Management, Co-management or No Management. Major Dilemmas in Southern African Freshwater Fisheries, pp. 180-201. Rome: FAO.

Heck, S., J. Ikwaput, C. Kirema-Mukasa, C. Lwenya, D. Murakwa, K. Odongkara, P. Onyango, J. Owino \& F. Sobo (2004), Cross-border Fishing and Fish Trade on Lake Victoria. Geneva/ Jinja: IUCN/LVFO.

Himbara, D. \& D. Sultan (1995), Reconstructing the Ugandan State and Economy: The Challenge of an International Bantustan. Review of African Political Economy 22, pp. 85-93.

Johnson, J.L. (2010), From Mfangano to Madrid: The Global Commodity Chain for Kenyan Nile Perch. Aquatic Ecosystem Health $\mathcal{E}$ Management 13, pp. 20-27.

Josupeit, H. (2009), Nile Perch Market Report, August 2009. Available at: <http:/ / www.thefishsite .com/articles/788/nile-perch-market-report-august -2009>. Accessed on 14 February 2014.

Kolding, J. \& P. van Zwieten (2011), The Tragedy of Our Legacy: How Do Global Management Discourses Affect Small Scale Fisheries in the South? Forum for Development Studies 38, pp. 26797.

Lake Victoria Fisheries Organization (LVFO) (2004) Lake Victoria Fisheries Statistical Databases/Summaries. Frame Surveys 2000 \& 2002 - Summary. Available at: <www.inweh.unu .edu/lvfo/frame_survey2000_2002.htm>. Accessed on 13 November 2011.

Lwenya, C. \& E. Yongo (2012), The Fisherman's Wife. Vulnerabilities and Strategies in the Local Economy: The Case of Lake Victoria, Kenya. Signs 37, pp. 566-573.

McCormack, F. (2010), Fish Is My Daily Bread: Owning and Transacting in Maori Fisheries. Anthropological Forum 20, pp. 19-39.

Medard, M. (2012), Relations Between People, Relations About Things: Gendered Investment and the 
Case of the Lake Victoria Fishery, Tanzania. Signs 37 , pp. 555-566.

Nunan, F. (2010), Mobility and Fisherfolk Livelihoods on Lake Victoria: Implications for Vulnerability and Risk. Geoforum 41, pp. 776-785.

Pitcher, T. \& D. Preikshot (2001), RAPFish: A Rapid Appraisal Technique to Evaluate the Sustainability Status of Fisheries. Fisheries Research 49, pp. 255-270.

Platteau, J.-P. (1989), The Dynamics of Fisheries Development in Developing Countries: A General Overview. Development E $\mathcal{E}$ Change 20, pp. 565-597.

Ponte, S. (2007), Bans, Tests and Alchemy: Food Safety Regulation and the Uganda Fish Export Industry. Agriculture and Human Values 27, pp. 179193.

Pringle, R. (2005), The Nile Perch in Lake Victoria: Local Responses and Adaptations. Africa 75, pp. 510-537.
Reynolds, J. \& W. Ssali (1990), Lake Victoria Fisheries Industrialisation: Recent Developments in Uganda. Rome: FAO.

Ruben, R. M. Slingerland \& H. Nijhoff (2006), Agro-food Chains and Networks for Development. Amsterdam: Springer.

SAlmi, P. (2005), Rural Pluriactivity as a Coping Strategy in Small-scale Fisheries. Sociologia Ruralis 45 , pp. 22-36.

SEDAWOG (1999), The Survey of Lake Victoria's Fishers (LVFRP/TECH/99/05). Jinja: The Lake Victoria Fisheries Research Project.

Stewart, K., R. Lewison, D. Dunn, R. BJorkland, S. Kelez, P. Halpin \& L. Crowder (2010), Characterizing Fishing Effort and Spatial Extent of Coastal Fisheries. PLoS ONE 5, pp. 1-8.

Wilson, D. (1993), Fisheries Management on Lake Victoria, Tanzania. Paper presented at the Annual Meeting of the African Studies Association. 4-7 December, Toronto. 